\title{
Molecular docking and inhibition studies on the interactions of Bacopa monnieri's potent phytochemicals against pathogenic Staphylococcus aureus
}

Talha Bin Emran 1,2*, Md Atiar Rahman², Mir Muhammad Nasir Uddin³, Raju Dash', Md Firoz Hossen', Mohammad Mohiuddin ${ }^{1}$ and Md Rashadul Alam

\begin{abstract}
Background: Bacopa monnieri Linn. (Plantaginaceae), a well-known medicinal plant, is widely used in traditional medicine system. It has long been used in gastrointestinal discomfort, skin diseases, epilepsy and analgesia. This research investigated the in vitro antimicrobial activity of Bacopa monnieri leaf extract against Staphylococcus aureus and the interaction of possible compounds involved in this antimicrobial action.

Methods: Non-edible plant parts were extracted with ethanol and evaporated in vacuo to obtain the crude extract. A zone of inhibition studies and the minimum inhibitory concentration (MIC) of plant extracts were evaluated against clinical isolates by the microbroth dilution method. Docking study was performed to analyze and identify the interactions of possible antimicrobial compounds of Bacopa monnieri in the active site of penicillin binding protein and DNA gyrase through GOLD 4.12 software.

Results: A zone of inhibition studies showed significant $(p<0.05)$ inhibition capacity of different concentrations of Bacopa monnieri's extract against Staphylococcus aureus. The extract also displayed very remarkable minimum inhibitory concentrations ( $\geq 16 \mu \mathrm{g} / \mathrm{ml}$ ) which was significant compared to that $(\geq 75 \mu \mathrm{g} / \mathrm{ml})$ of the reference antibiotic against the experimental strain Staphylococcus aureus. Docking studies recommended that luteolin, an existing phytochemical of Bacopa monnieri, has the highest fitness score and more specificity towards the DNA gyrase binding site rather than penicillin binding protein.

Conclusions: Bacopa monnieri extract and its compound luteolin have a significant antimicrobial activity against Staphylococcus aureus. Molecular binding interaction of an in silico data demonstrated that luteolin has more specificity towards the DNA gyrase binding site and could be a potent antimicrobial compound.
\end{abstract}

Keywords: Bacopa monnieri L, Staphylococcus aureus, Antibacterial activity, MIC, Molecular docking, GOLD, in silico drug discovery

\footnotetext{
*Correspondence: talhabmb@gmail.com

${ }^{1}$ Department of Pharmacy, BGC Trust University Bangladesh, Chittagong

4000, Bangladesh

${ }^{2}$ Department of Biochemistry and Molecular Biology, University of

Chittagong, Chittagong 4331, Bangladesh

Full list of author information is available at the end of the article
} 


\section{Background}

Effective therapeutic options to combat Staphylococcus aureus infection are still limited. And this makes a major burden to control Staphylococcus aureus [1]. S. aureus is a commensal Gram-positive bacterium, which colonizes in human nasal mucosa either permanently or transiently [2], causing severe infections eventually $[3,4]$. But the clinical symptoms are not visualized until the immune system is affected [5]. However, the major problem in controlling the $S$. aureus infection is the occurrence of multi-drug resistance produced mainly due to the misuse of antibiotics. This is also caused by the treatment of nonbacterial infections with antibiotics or inadequate compliance with the regulations for drug ingestion. Therefore, new therapeutic molecule is an urgence to be introduced as antibiotic in the treatment of multi-drug resistant S. aureus. Several studies have proposed that phytocompounds are the best alternative to develop therapies for multidrug resistant bacterial infections [6-8].

Bacopa monnieri (L.) Wellst. (Family: Plantaginaceae) is known as Herpestis monniera. It is a water hyssop or "Brahmi" and is reputed as Ayurvedic medicine. It is used for gastrointestinal discomfort, rejuvenation, promoting memory and intellect, skin disorders, epilepsy, pyrexia and analgesia [9]. Number of biologically active compounds has been isolated from this plant. GC-MS analysis of the leaf extract of this plant showed the presence of tetracyclic triterpenoids, saponin, bacosides A and $\mathrm{B}$ phytosterols, hersaponin, D-mannitol, flavonoids viz., luteolin-7-glucoside, apigenin-7-glucocronide, alkaloids such as nicotine and herpestine, betulic acid, $\beta$-sitosterol, stigma-sterol and its esters, aspartic acid, glutamic acid and serine [10]. Despite enormous possibilities of this plant, no compound-activity relationship study has been conducted yet to investigate the phytochemicals responsible for its antimicrobial action. This research evaluates the in vitro antimicrobial activity of $B$. monnieri against $S$. aureus establishing the interaction of existing phytocompounds involved in this antimicrobial activity through an in silico molecular docking analysis $[11,12]$.

\section{Methods}

\section{Media and chemicals}

Mueller-Hinton broth and agar media (Hi media, India; final $\mathrm{pH} 7.3 \pm 0.2$ at $25^{\circ} \mathrm{C}$ ), was used for the determination of MIC and antibacterial activity. Tetracycline (50 $\mu \mathrm{g} /$ disk) and ampicillin disks (50 $\mu \mathrm{g} /$ disk) were procured from Oxoid, England.

\section{Collection and identification of plant materials}

The plant B. monnieri was selected by Talha Bin Emran, Lecturer, Department of Pharmacy, BGC Trust University Bangladesh. Fresh leaves of B. monnieri were collected from the Chittagong University hilly forest on December 2013. The plant was identified by Dr. Shaikh Bokhtear Uddin, Taxonomist and Associate Professor, Department of Botany, University of Chittagong-4331, Bangladesh. A voucher specimen (Accession Number: 36285 ) containing the identification characteristics of the plant has been preserved in the Bangladesh National Herbarium for future reference.

\section{Preparation of crude ethanol extract}

The fresh leaves of $B$. monnieri were washed immediately after collection and chopped into small pieces, air dried and ground (Moulinex Blender AK-241, Moulinex, France) into powder (40-80 mesh, $500 \mathrm{~g}$ ). The resulting powder was soaked in an Erlenmeyer flask of absolute ethanol $(2.0 \mathrm{~L}$, at room temperature) and left for seven days allowing occasional stirring of the flask. Filtrate obtained through cheesecloth and Whatman filter paper No. 1 was concentrated under reduced pressure at the temperature below $50^{\circ} \mathrm{C}$ using a rotatory evaporator (RE 200, Bibby Sterling Ltd., UK). The extracts (yield $4.4-5.6 \% \mathrm{w} / \mathrm{w})$ were all placed in glass Petri dishes $(90 \times 15 \mathrm{~mm}$, Pyrex, Germany) to allow an air-dry for complete evaporation of solvent.

\section{Study of antibacterial activity Bacterial strain}

Gram-positive Staphylococcus aureus (ATCC6538) was used for screening the antibacterial effect of the plant extract. Bacterial strain was collected from the Microbiology Division of Bangladesh Council of Scientific and Industrial Research (BCSIR), Chittagong-4220, Bangladesh.

\section{Preparation of sample solutions}

Small amount (1, 2 and $3 \mathrm{mg}$ ) of solid sample was dissolved in a definite volume (1 ml) of DMSO to make a solution of $1 \mathrm{mg} / \mathrm{ml}$. DMSO was chosen as solvent because it does not have any inhibitory effect on bacterial cultures and it has extraordinary capacity to dissolve solid sample completely.

\section{Media preparation}

The bacterial strain was grown and maintained on Standard Nutrient Agar (DIFCO) media (Hi media, India) at $37^{\circ} \mathrm{C}$ and $\mathrm{pH} 7.3 \pm 0.2$. The bacterium was sub-cultured overnight in nutrient agar broth which was further adjusted to obtain turbidity comparable to McFarland (0.5) standard when required. Test tube slants of nutrient agar medium were prepared for the maintenance of culture. Then a small amount of the collected microorganism was transferred to the test tubes with the help of sterilized needles. A number of test tubes were freshly cleaned for bacterial pathogen. The inoculated slants were inoculated at temperature below laboratory condition. 
Antibacterial screening through disk diffusion technique

The antibacterial activity of the extract was determined by disk diffusion technique (National Committee for Clinical Laboratory Standards, NCCLS, 2002). The test microbes were taken from the broth culture with inoculating loop and transferred to test tubes containing $5.0 \mathrm{ml}$ sterile distilled water. The inoculums were added until the turbidity was equal to $0.5 \mathrm{McFarland}$ standards. Cotton swab was then used to inoculate the test tube suspension onto the surface of the Muller Hinton agar plate and the uniformly swabbed plates were then allowed to dry. On the dry inoculated surfaces prepared paper disks were placed as follows. Sterilized Whatman paper disks (6 $\mathrm{mm}$ in diameter) were prepared previously by punching the filter paper with the help of a punch machine. After that the disks were placed upon $0.5 \mathrm{ml}$ of the desired solution (1, 2 and $3 \mathrm{mg} /$ disk) of the extract. After each application the disks were allowed to the temperature $40^{\circ} \mathrm{C}$ (one minute) for drying purposes. The disks containing plant extract were placed with blunt-nosed thumb forceps on the inoculated plates at equidistance in a circle. These plates were kept for 4-6 $\mathrm{h}$ at a low temperature $\left(<8^{\circ} \mathrm{C}\right)$ to allow for diffusion of the extract from the disk into the medium. The same was done for negative control (ethanol). The plates were incubated at $37^{\circ} \mathrm{C}$ for $24 \mathrm{~h}$. The experiment was conducted in triplicates. Antimicrobial activity was determined by a measurement of the inhibition zone diameter $(\mathrm{mm})$ around each test organism.

\section{Minimum inhibitory concentration (MIC) determination}

Minimum inhibitory concentration was determined by the microdilution method using serially diluted ( 2 folds) plant extract according to the National Committee for Clinical Laboratory Standards (NCCLS) (National Committee for Clinical Laboratory Standards, 2000). The MIC of the extract was determined by the dilution of B. monnieri extract with the concentrations of $0.0-25$, $0.0-50,0.0-75,0.0-100,0.0-125$, and $0.0-150 \mu \mathrm{g} / \mathrm{ml}$. Equal volume of each extract and nutrient broth was mixed in a test tube. Specifically $0.1 \mathrm{ml}$ of standardized inoculum $\left(1-2 \times 10^{7} \mathrm{cfu} / \mathrm{ml}\right)$ was added in each tube. The tubes were incubated aerobically at $37^{\circ} \mathrm{C}$ for 18 $24 \mathrm{~h}$. Two control tubes were maintained for each test batch. These included antibiotic control (a tube containing extract and growth media without inoculum) and organism control (a tube containing the growth medium, saline and the inoculum). The lowest concentration (highest dilution) of the extract that produced no visible bacterial growth (no turbidity) was considered as MIC.

\section{Statistical analysis}

All data are presented as mean \pm standard deviation (SD). The data were analyzed by a statistical software statistical package for social science (SPSS, version 18.0, IBM Corporation, NY, USA) using Tukey's multiple range post hoc tests. The values were considered significantly different at $p<0.05$.

\section{Docking approach}

To have a better understanding about the inhibitory mechanism as well as the mode of interactions of the phytochemical compounds of the crude extract, docking analysis was accomplished using the GOLD 4.12 package. Two primary drug-target-pathways, i.e., penicillinbinding protein [13] and DNA gyrase [14] of S. aureus were subject to forecast the mechanism of plant derived compounds. Protein X-ray structure pdb ID: 3vsl and 3g7b was retrieved from protein data bank [15] and compared with standard inhibitor orientation in crystal structure. From the literature review, all compounds represented in Figure 1 were drawn in Symyx Draw 4.0 and to prepare for docking using the Sybyl 7.3 Molecular Modeling Suite of Tripos, Inc. Three dimensional (3D) conformations generated by using Concord 4.0 [16]; hydrogen atoms were added and charges were loaded using the Gasteiger and Marsili charge calculation method [17]. Basic amines were protonated and acidic carboxyl groups were de-protonated prior to charge calculation. The ligands were minimized with the Tripos Force Field prior to docking using the Powell method with an initial Simplex [18] optimization and 1000 interactions or gradient termination at $0.01 \mathrm{kcal} /\left(\mathrm{mol}^{*} \mathrm{~A}\right)$. The input ligand file format was mol2 for all docking programs investigated. Three dimensional structure of standard drugs i.e., penicillin $G$ and ciprofloxacin was occupied from zinc databases. The docking tool "GOLD" utilizes genetic algorithm to explore the rotational flexibility of receptor hydrogen's and ligand conformational flexibility [19]. Such GOLD docking was carried out using the wizard with default parameters population size (100); selection pressure (1.1); number of operations $(10,000)$; number of islands (1); niche size (2); and operator weights for migrate (0), mutate (100), and crossover (100). The active site with a $10 \AA$ radius sphere was defined by selecting an active site residue of protein. Default genetic algorithm settings were used for all calculations and a set of 10 solutions was saved for each ligand. GOLD was used by a GoldScore fitness function. GoldScore is a molecular mechanism like function and has been optimized for the calculation of binding positions of ligand. It takes into account for four terms:

$$
\begin{aligned}
\text { Fitness }= & S_{(\text {hb_ext })}+1.3750 * S_{(\text {vdw_ext })}+S_{\left(\mathrm{hb} \_ \text {int }\right)} \\
& +1.0000 * S_{(\text {int })} \\
\mathbf{S}_{(\text {int })}=S_{(\text {vdw_int })}+ & S_{(\text {tors })}
\end{aligned}
$$

Where, $\mathrm{S}_{\text {hb_ext }}$ is the protein-ligand hydrogen bonding 
<smiles>O=c1cc2oc(-c3ccc(O)cc3)cc(O)c-2c(O)c1</smiles>

Apigenin

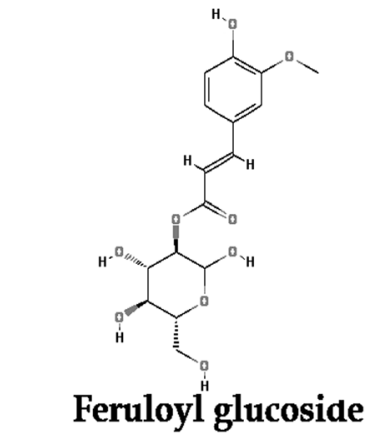

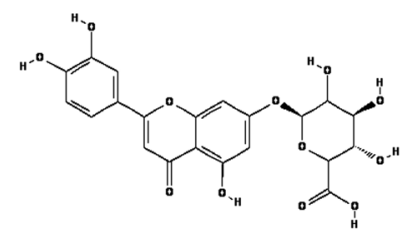

loliolide

Luteolin 7-glucuronide

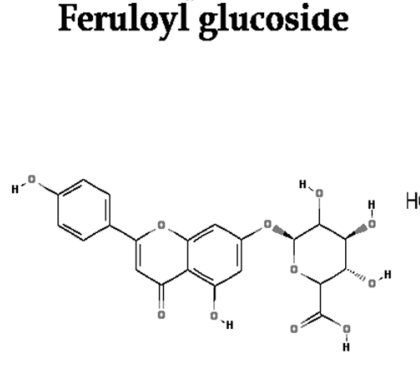

Apigenin 7-glucuronide<smiles>OC[C@@H](O)[C@@H](O)[C@H](O)[C@H](O)CO</smiles>

D mannitol

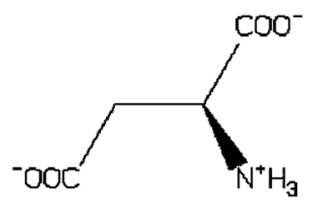

L-Aspartic acid<smiles>O=c1cc(-c2ccc(O)c(O)c2)oc2cc(O)cc(O)c12</smiles>

Luteolin

Figure $12 D$ structure of all compounds of $B$. monnieri.

and $\mathrm{S}_{\mathrm{vdw} \text { ext }}$ are the Vanderwaals interactions between protein and ligand. $\mathrm{S}_{\mathrm{hb} \_ \text {int }}$ are the intramolecular hydrophobic interactions whereas $\mathrm{S}_{\mathrm{vdw}_{-} \text {int }}$ is the contribution due to intramolecular strain in the ligand.

\section{Results}

\section{In vitro antimicrobial assay}

Results for the antibacterial activity of $B$. monnieri extract showed that the mean zone of inhibition (13.0-15.0 mm) produced by the extract was close to those produced by the reference antibiotics, i.e., tetracycline and ampicillin which had the zone of inhibitions between 16 to $20 \mathrm{~mm}$. The extract of three different concentrations (1,2 and $3 \mathrm{mg} /$ disk) produced significant $(p<0.05)$ zone of inhibition against $S$. aureus and the values were $13.33 \pm 2.08$, $13.33 \pm 2.08$ and $15.33 \pm 1.52$ for 1,2 and $3 \mathrm{mg} /$ disk, respectively. The result of antibacterial activity of $B$. monnieri ethanol extract is shown in Table 1.

\section{Minimum inhibitory concentration}

The minimum inhibitory concentrations of $B$. monnieri leaf extract for different bacterial strains were ranged from 25 to $100 \mu \mathrm{l} / \mathrm{ml}$ (Table 2). The arbitrary MIC against the Gram-positive bacteria S. aureus was greater than or equal to 75 for the extract and 16 for the reference antibiotic tetracycline.

\section{Docking experiments}

Considering the results obtained in in vitro study, it was thought worthy to perform molecular docking studies which correlate both in silico and in vitro results. Docking studies are used at different stages of drug discovery such as to predict a ligand-receptor interaction and also to rank the compounds based on the binding energies or fitness score [20]. In our present study, docking of tested compounds with the primary drug pathway for $S$. aureus was performed, and the corresponding fitness score was also determined as shown in Table 3. The interacting energies followed the order of the best fitness core. Highest fitness scored compound was further subjected to compare its binding pattern and molecular interaction with the standard drug penicillin $\mathrm{G}$ and ciprofloxacin.

In the docking studies of DNA gyrase binding site, luteolin among the other tested compounds has the 
Table 1 in vitro antibacterial activity of B. monnieri ethanol extract

\begin{tabular}{|c|c|c|c|c|c|c|c|}
\hline \multirow{2}{*}{$\begin{array}{l}\text { Bacterial } \\
\text { type }\end{array}$} & \multirow[t]{3}{*}{ Test organism } & \multirow{3}{*}{$\begin{array}{l}\text { Source ID } \\
\text { (ATCC) }\end{array}$} & \multicolumn{5}{|c|}{ Diameter of zone of inhibition ( $\mathrm{mm}$ ) } \\
\hline & & & \multicolumn{3}{|c|}{ Bacopa monnieri } & \multicolumn{2}{|l|}{ Standard antibiotics } \\
\hline Gram + ve & & & $1 \mathrm{mg} / \mathrm{disk}$ & $2 \mathrm{mg} /$ disk & $3 \mathrm{mg} /$ disk & Tetracycline $(50 \mu \mathrm{g} /$ disk) & Ampicillin (50 $\mu \mathrm{g} / \mathrm{disk})$ \\
\hline & Staphylococcus aureus & 6538 & $13.33 \pm 2.08^{\mathrm{a}}$ & $13.33 \pm 2.08^{b}$ & $15.33 \pm 1.52^{c}$ & $16.00 \pm 3.54^{d}$ & $20.00 \pm 1.60^{e}$ \\
\hline
\end{tabular}

Data are shown as mean \pm SD for triplicate of concentration. Different superscript letters (a-e) shown in the data indicate that the values are significantly different (Tukey's multiple range, post hoc test, $p<0.05$ ) from each other.

highest fitness score 53.77 compared with the highest fitness score 46.48 of ciprofloxacin. Molecular binding pattern of ciprofloxacin revealed that it has two hydrogen bonds with ARG144 and GLY85 consisting of hydrogen bonding distances $2.634 \AA$ and $2.476 \AA$ shown in Figure 2. These two hydrogen bonding residues in luteolin are found to be similar with different hydrogen bonds viz. 2.641 $\AA$ for ARG144 and 2.520 ̊ for GLY85. Additionally, it also formed two other hydrogen bonds with ARG84 and ASP81 having a bonding distance of $2.932 \AA$ and $2.956 \AA$.

For the most potent inhibitor of penicillin binding protein, luteolin showed the highest fitness score among the other tested compounds viz., 45.35 fitness score compared to its reference standard drug penicillin G 46.48. In context of different binding patterns, luteolin has formed the three hydrogen bonds SER429, THR621 and THR619 where bonding distances were 3.020, 2.798 and 2.331. On the other hand, reference drug penicillin $\mathrm{G}$ formed hydrogen bonds with ASN450, SER778, THR621 and GLN524 with corresponding hydrogen bonds $2.956 \AA$, $2.968 \AA$, $2.556 \AA$ and $3.031 \AA$, respectively. Binding mode and related interactions are summarized in Figure 3.

The emergence of bacterial resistance to current clinical drugs has brought intention to develop novel antimicrobial agents for selectively inhibiting the constantly evolved bacterial targets which have been also continually promoted with challenges. Presently known target of Staphyloccus sp. includes PBP (penicillin binding protein) of peptidoglycan biosynthesis pathway where betalactam antibiotics were known to be effective against it [21]. A different prescribing drug i.e. Fluroquinolone, DNA Gyrase A enzyme which is essential for the replication and super-coiling of DNA, is the main target at this case. But according to Stephen et al., a highly significant association between Levofloxacin and Ciprofloxacin

Table 2 Minimum inhibitory concentrations (MIC) of B. monnieri and tetracycline against Staphylococcus aureus

\begin{tabular}{lll}
\hline Test organism & $\begin{array}{l}\text { MIC of Bacopa monnieri } \\
\text { extract }(\boldsymbol{\mu g} / \mathbf{m l})\end{array}$ & $\begin{array}{l}\text { MIC of tetracycline } \\
(\boldsymbol{\mu g} / \mathbf{m l})\end{array}$ \\
\hline Staphylococcus aureus & $\geq 75$ & $\geq 16$ \\
\hline
\end{tabular}

treatment and consequent isolation of MRSA is reported [22]. However, in this research, molecular docking analysis suggested that luteolin has the more specificity towards the DNA gyrase binding site than penicillin binding protein. Regarding the obtained results, luteolin could serve as an appropriate starting point for designing new chemical entities as potent $S$. aureus inhibitor.

\section{Discussion}

Plants have long been a very important source of drug and many plants have been screened whether they contain compounds with therapeutic activity. Therefore, it is vital to evaluate the antimicrobial activity of $B$. monnieri. The bacterial strain was chosen to be studied as it is an important pathogen and rapidly develop antibiotic resistance with its increased uses. In disk diffusion technique, the mean zone of inhibition produced by the commercial antibiotic, tetracycline and ampicillin, was larger than that produced by ethanol extract. It may be attributed to the fact that the plant extract being in crude form contains a smaller concentration of bioactive compounds. In classifying the antimicrobial activity it would be generally expected that a greater number would be active against Gram-positive than Gram-negative bacteria. Apart from this, the higher MIC value is an indication that either the plant extracts are less effective on bacteria or the organism has the potential to develop antibiotic resistance. On the contrary, the low MIC value for bacteria is an indication of the higher efficacy of the plant extracts.

Most of the pathogenic bacteria have developed resistance to currently available antibiotics due to their misuse or overuse. This situation has led to an urgent need to explore different sources of efficient, less toxic and cost-effective antimicrobial agents [23,24]. Medicinal plants play a major role and constitute the backbone of traditional medicine. According to the World Health Organization (WHO) estimate, $80 \%$ of populations in developing countries rely exclusively on traditional medicine for their healthcare need. Moreover, $20 \%$ of the available allopathic drugs have an active principal obtained from higher plants [25]. Recognizing the significance of indigenous medicinal plants WHO states in its 1997 guideline that locally available effective plants may 
Table 3 Gold fitness score of B. monnieri's all compounds against DNA gyrase and penicillin binding protein

\begin{tabular}{|c|c|c|c|c|c|c|c|c|c|c|}
\hline \multicolumn{6}{|l|}{ DNA gyrase } & \multicolumn{5}{|c|}{ Penicillin binding protein } \\
\hline Compound name & Fitness score & $S\left(h b \_e x t\right)$ & S(vdw_ext) & $S\left(h b \_i n t\right)$ & $S$ (int) & Fitness Score & $S\left(h b \_e x t\right)$ & S(vdw_ext) & $S$ (hb_int) & S(int) \\
\hline Apigenin & 46.59 & 5.57 & 36.00 & 0.00 & -8.48 & 41.73 & 7.29 & 30.70 & 0.00 & -7.77 \\
\hline Rosavin & 51.58 & 5.44 & 42.31 & 0.00 & -12.03 & 41.96 & 8.88 & 31.27 & 0.00 & -9.92 \\
\hline Quercetin & 45.71 & 6.04 & 37.32 & 0.00 & -11.64 & 40.14 & 9.37 & 30.55 & 0.00 & -11.23 \\
\hline Feruloyl glucoside & 49.23 & 8.14 & 42.78 & 0.00 & -17.74 & 32.42 & 4.76 & 35.88 & 0.00 & -21.68 \\
\hline Loliolide & 29.61 & 0.10 & 23.41 & 0.00 & -2.68 & 31.02 & 3.34 & 22.10 & 0.00 & -2.71 \\
\hline Luteolin-7-glucoside & 47.87 & 10.04 & 42.46 & 0.00 & -20.56 & 43.85 & 2.46 & 42.08 & 0.00 & -16.48 \\
\hline Apigenin-7-glucocronide & 45.63 & 8.34 & 39.19 & 0.00 & -16.59 & 43.35 & 8.74 & 37.80 & 0.00 & -17.36 \\
\hline D-mannitol & 32.55 & 9.88 & 23.13 & 0.00 & -9.13 & 30.21 & 8.15 & 20.48 & 0.00 & -6.11 \\
\hline L-asperatic acid & 33.35 & 17.74 & 17.07 & 0.00 & -7.86 & 28.29 & 14.01 & 16.69 & 0.00 & -8.66 \\
\hline Luteolin & 53.77 & 11.23 & 37.44 & 0.00 & -8.94 & 45.35 & 7.81 & 41.67 & 0.00 & -19.77 \\
\hline Penicillin G & - - - & $-\cdots--$ & $-\cdots---$ & --.-- & -...- & 46.48 & 2.62 & 35.14 & 0.00 & -4.46 \\
\hline Ciprofloxacine & 46.48 & 0.21 & 42.47 & 0.00 & -8.94 & -..-.-. & -..-.- & -..... & -...- & 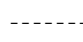 \\
\hline
\end{tabular}




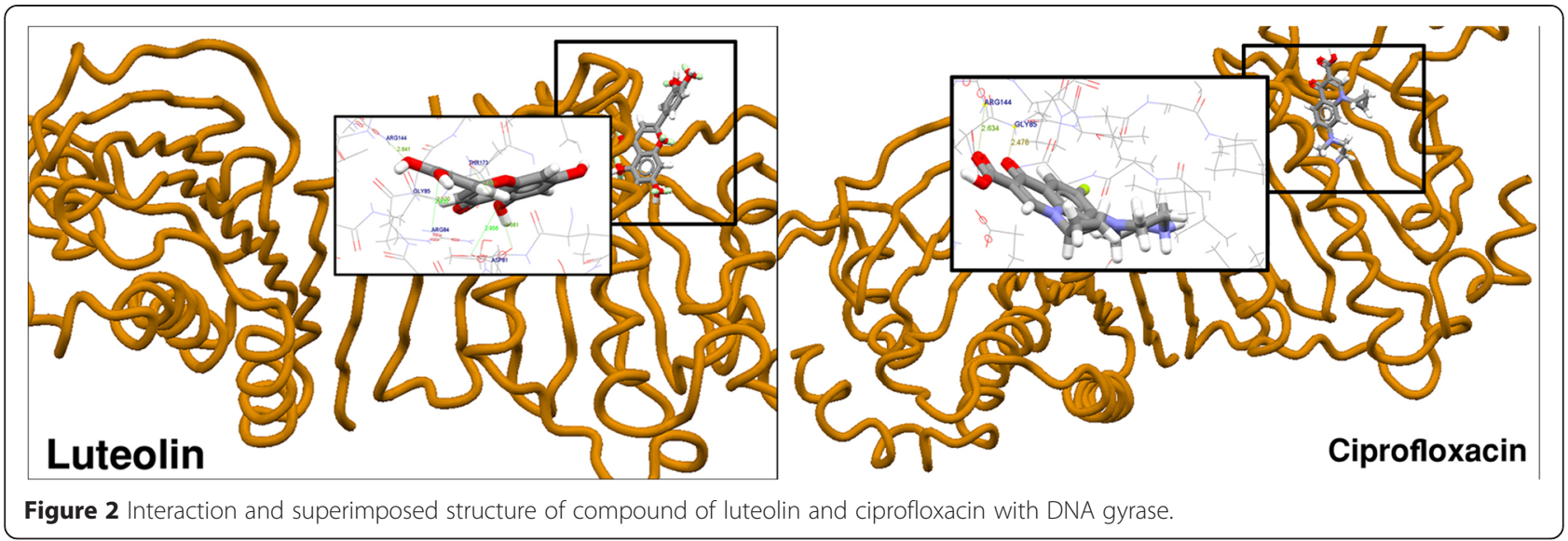

be used as substitutes for drugs. Research work on medicinal plants and exchange of obtained information will go a long way in scientific exploration of medicinal plants for the benefit of mankind. This will ultimately decrease our dependence on synthetic drugs [26]. Plant synthesizes natural products as its chemical weapon that arrests the growth of environmental microbes [27] and some plants inhibit the growth of potential human pathogens too. In the current study, in vitro MIC of B. monnieri leaf parts, prescribed in indigenous system of medicine, that are available in the local market or growing in Bangladesh and India were evaluated against local clinical bacterial isolate of S. aureus. Determination of MIC of this plant is important to find out the best plant that eradicates infectious agents (Table 2). Clinicians also select the antibiotic on the basis of their MIC value to treat infectious diseases. Plant extracts having MIC below $8000 \mu \mathrm{g} / \mathrm{ml}$ have been reported as therapeutically effective [28]. Our results for B. monnieri implicated a significant MIC value (below or equal to $75 \mu \mathrm{g} / \mathrm{ml}$ ) in this study. This significance suggests that we have identified antimicrobial activity of plant that is effective for arresting the growth of $S$. aureus causing hospital-,-acquired- and opportunisticinfections.

\section{Conclusions}

B. monnieri extract and its compound luteolin have a significant antimicrobial activity against $S$. aureus. Molecular binding interaction of in silico data demonstrated that luteolin has more specificity towards the DNA gyrase binding site and could be a potent antimicrobial compound. However several scientific reports manifested that lead-drug discovery projects on the basis of binding efficiency indices would afford bioactive compounds with better pharmacokinetic outcomes. Hence, isolated bioactive compounds should be employed for establishing more rational structure activity relationships in the era of antimicrobial drug development.

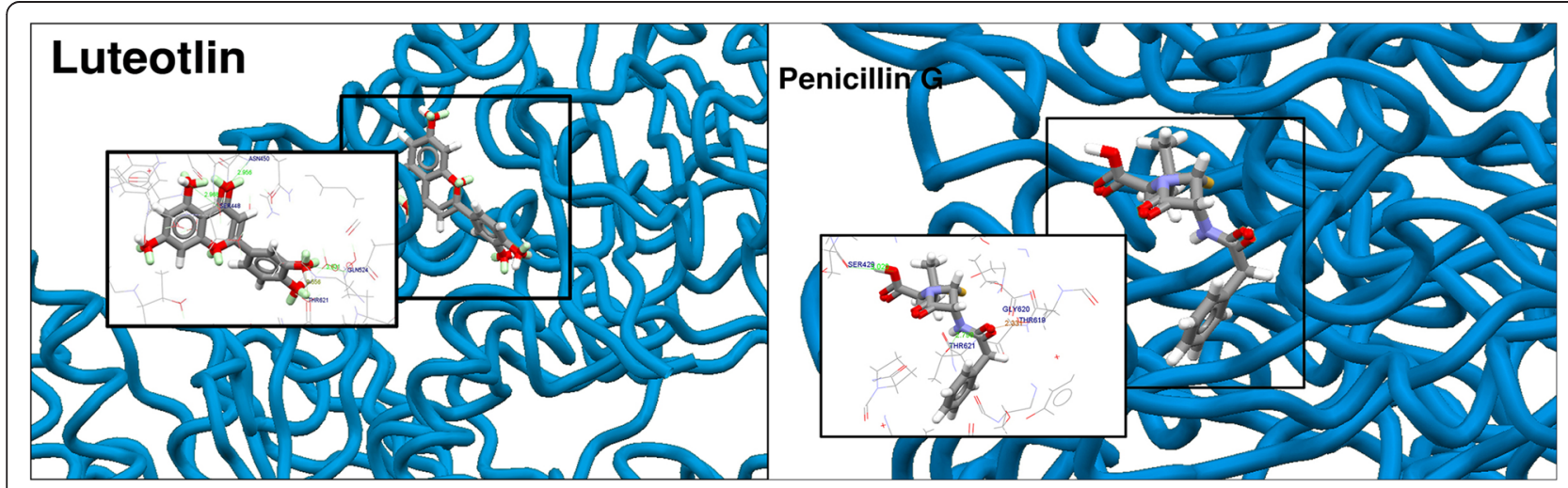

Figure 3 Interaction and superimposed structure of compound of luteolin and penicillin G with penicillin binding protein. 


\section{Competing interests}

The authors declare that they have no competing interests.

\section{Authors' contributions}

TBE has designed the study, performed data analysis and interpretation and written the manuscript. MAR has revised the whole manuscript and also helped in the grammatical corrections. MMNU has modified the in silico sections. RD has performed data analysis and written the in silico sections. MFH and MM have participated in experiments, data collection and literature search. MRA has provided assistance in taxonomical identification and collections of voucher specimen's number of the plant. All authors read and approved the final version of the manuscript.

\section{Acknowledgements}

Authors are thankful to Dr. Shaikh Bokhtear Uddin, Taxonomist and Associate Professor, Department of Botany, University of Chittagong, Chittagong-4331, Bangladesh for identifying the plant sample. We are also grateful to Bangladesh Council of Scientific and Industrial Research (BCSIR), Chittagong-4220, Bangladesh for supplying the microbial strains.

\section{Author details}

${ }^{1}$ Department of Pharmacy, BGC Trust University Bangladesh, Chittagong 4000, Bangladesh. ${ }^{2}$ Department of Biochemistry and Molecular Biology, University of Chittagong, Chittagong 4331, Bangladesh. ${ }^{3}$ Department of Pharmacy, University of Chittagong, Chittagong 4331, Bangladesh.

Received: 10 July 2014 Accepted: 1 March 2015

Published online: 17 April 2015

\section{References}

1. Boucher HW, Talbot GH, Bradley JS, Edwards JE, Gilbert D, Rice LB, et al. Bad bugs, no drugs: no ESKAPE! An update from the Infectious Diseases Society of America. Clin Infect Dis. 2009:48(1):1-12.

2. Kluytmans J, van Belkum A, Verbrugh H. Nasal carriage of Staphylococcus aureus: epidemiology, underlying mechanisms, and associated risks. Clin Microbiol Rev. 1997;10(3):505-20.

3. Kuehnert MJ, Hill HA, Kupronis BA, Tokars Jl, Solomon SL, Jernigan DB. Methicillin-resistant-Staphylococcus aureus hospitalizations, United States. Emerg Infect Dis. 2005;11(6):868-72.

4. Klevens RM, Morrison MA, Nadle J, Petit S, Gershman K, Ray S, et al. Invasive methicillin-resistant Staphylococcus aureus infections in the United States. Jama. 2007;298(15):1763-71.

5. Diefenbeck M, Mennenga U, Guckel P, Tiemann AH, Muckley T, Hofmann GO. Vacuum-assisted closure therapy for the treatment of acute postoperative osteomyelitis. Z Orthop Unfall. 2011;149:336-41.

6. Garo E, Eldridge GR, Goering MG, DeLancey PE, Hamilton MA, Costerton JW, et al. Asiatic acid and corosolic acid enhance the susceptibility of Pseudomonas aeruginosa biofilms to tobramycin. Antimicrob Agents Chemother. 2007;51(5):1813-7.

7. Coutinho HD, Costa JG, Lima EO, Falcao-Silva VS, Siqueira-Junior JP. Enhancement of the antibiotic activity against a multiresistant Escherichia coli by Mentha arvensis L. and chlorpromazine. Chemotherapy. 2008;4:328-30.

8. Coutinho HD, Costa JG, Lima EO, Falcao-Silva VS, Siqueira Jr JP. Herbal therapy associated with antibiotic therapy: potentiation of the antibiotic activity against methicillin-resistant Staphylococcus aureus by Turnera ulmifolia L. BMC Complement Altern Med. 2009;9(13):1472-6882.

9. Aguiar S, Borowski T. Neuropharmacological review of the nootropic herb Bacopa monnieri. Rejuvenation Res. 2013;16(4):313-26.

10. Chopra RNNL, Chopra IC. Glossary of Indian Medicinal Plants. New Delhi: Council of Scientific and Industrial Research; 1956. p. 32.

11. Ghosh S, Nie A, An J, Huang Z. Structure-based virtual screening of chemical libraries for drug discovery. Curr Opin Chem Biol. 2006;10(3):194-202.

12. Dash R, Emran TB, Uddin MM, Islam A, Junaid M. Molecular docking of fisetin with $A D$ associated $A C h E, A B A D$ and BACE1 proteins. Bioinformation. 2014;10(9):562-8.

13. Yoshida H, Kawai F, Obayashi E, Akashi S, Roper DI, Tame JR, et al. Crystal structures of penicillin-binding protein 3 (PBP3) from methicillin-resistant Staphylococcus aureus in the apo and cefotaxime-bound forms. J Mol Biol. 2012;423(3):351-64.
14. Ronkin SM, Badia M, Bellon S, Grillot AL, Gross CH, Grossman TH, et al. Discovery of pyrazolthiazoles as novel and potent inhibitors of bacterial gyrase. Bioorg Med Chem Lett. 2010;20(9):2828-31.

15. Berman HM, Westbrook J, Feng Z, Gilliland G, Bhat TN, Weissig H, et al. The Protein Data Bank. Nucleic Acids Res. 2000;28(1):235-42.

16. Hevener KE, Zhao W, Ball DM, Babaoglu K, Qi J, White SW, et al. Validation of molecular docking programs for virtual screening against dihydropteroate synthase. J Chem Inf Model. 2009;49(2):444-60.

17. Hristozov DP, Oprea TI, Gasteiger J. Virtual screening applications: a study of ligand-based methods and different structure representations in four different scenarios. J Comput Aided Mol Des. 2007;21(10-11):617-40.

18. Osolodkin DI, Palyulin VA, Zefirov NS. Structure-based virtual screening of glycogen synthase kinase 3-beta inhibitors: analysis of scoring functions applied to large true actives and decoy sets. Chem Biol Drug Des. 2011;78(3):378-90.

19. Jones G, Willett P, Glen RC, Leach AR, Taylor R. Development and validation of a genetic algorithm for flexible docking. J Mol Biol. 1997;267(3):727-48.

20. Kitchen DB, Decornez H, Furr JR, Bajorath J. Docking and scoring in virtual screening for drug discovery: methods and applications. Nat Rev Drug Discov. 2004;3(11):935-49.

21. Hao H, Cheng G, Dai M, Wu Q, Yuan Z. Inhibitors targeting on cell wall biosynthesis pathway of MRSA. Mol Biosyst. 2012;8(11):2828-38.

22. Weber SG, Gold HS, Hooper DC, Karchmer AW, Carmeli Y. Fluoroquinolones and the risk for methicillin-resistant Staphylococcus aureus in hospitalized patients. Emerg Infect Dis. 2003;9(11):1415-22.

23. Russell AD. Bacterial resistance to disinfectants: present knowledge and future problems. J Hosp Infec. 1999;43(0):S57-68. Supplement 1.

24. Sheldon Jr AT. Antibiotic resistance: a survival strategy. Clin Lab Sci. 2005;18(3):170-80.

25. Gurib-Fakim A. Medicinal plants: traditions of yesterday and drugs of tomorrow. Mol Aspects Med. 2006;27(1):1-93.

26. Veerappan A, Miyazaki S, Kadarkaraisamy M, Ranganathan D. Acute and subacute toxicity studies of Aegle marmelos Corr., an Indian medicinal plant. Phytomedicine. 2007;14(2-3):209-15.

27. Gibbons S. Anti-staphylococcal plant natural products. Nat Prod Rep. 2004;21(2):263-77.

28. Fabry W, Okemo PO, Ansorg R. Antibacterial activity of East African medicinal plants. J Ethnopharmacol. 1998;60(1):79-84.

\section{Submit your next manuscript to BioMed Central and take full advantage of:}

- Convenient online submission

- Thorough peer review

- No space constraints or color figure charges

- Immediate publication on acceptance

- Inclusion in PubMed, CAS, Scopus and Google Scholar

- Research which is freely available for redistribution 